\title{
Tecnologias na escola: algumas experiências e possibilidades
}

\author{
Ítalo Modesto Dutra* \\ Rosália Procasko Lacerda*
}

\begin{abstract}
Resumo: A necessidade de transformar a sala de aula tem levado a maioria das escolas públicas e privadas ao uso de novas tecnologias e ao repensar de metodologias na tentativa de construir um currículo que contemple os interesses dos alunos e as mudanças globais que ocorrem tão rapidamente. Dessa forma, a pesquisa em sala de aula e o uso da Internet têm lugar de destaque no cenário educativo, embora, muitas vezes, não reflitam mudanças pedagógicas de fato, deixando de integrar-se ao currículo e transformando-se em meros apêndices da grade curricular. Pressupondo-se que a possibilidade de interagir com outros sujeitos seja o fundamental papel do uso da tecnologia na escola, pretendemos, neste artigo, refletir sobre alguns recursos da Internet utilizados com alunos e professores a partir de nossa experiência em parcerias com escolas públicas brasileiras.
\end{abstract}

Palavras-chave: Internet, interação, escola, construtivismo.

Abstract: The continuous transformations of school and society leads to a rational and efficient use of the new technologies as a way to rethink methods and curriculum with the main goal to respect students' needs and global changes. We assume that increase the possibilities of interaction with other teachers and students is, fundamentally, the role of technologies in school. We intent to show, in this paper, a little of our experience in using technology with another Public Brazilian Schools, and so discuss possibilities and new challenges of technology integration in the school.

Keywords: Internet, interaction, school, construtivism.

\footnotetext{
* Doutorando do PGIE, Mestre em Matemática pela UFRGS, Pesquisador do Laboratório de Estudos Cognitivos (LEC-UFRGS), Professor do Colégio de Aplicação da UFRGS, e-mail: italo@ cap.ufrgs.br

** Mestre em Estudos da Linguagem pela UFRGS, Pesquisadora do Laboratório de Estudos Cognitivos (LEC-UFRGS), Professora do Colégio de Aplicação da UFRGS, e-mail: rosalia@ cap.ufrgs.br 


\section{Por que interagir? E com quem?}

Tomando-se a aprendizagem sob uma perspectiva construtivista, é fundamental uma interação entre o sujeito e o objeto de seu interesse (Nitzke, 2002). Dessa forma uma nova concepção pedagógica se faz necessária, já que o aprender não está centrado no professor, mas no aluno, e sua participação determina a construção do conhecimento e o desenvolvimento de habilidades cognitivas. O trabalho individual, fomentado tradicionalmente, dá lugar ao trabalho em equipe o qual promove o compartilhamento das idéias e das experiências. Além disso, o aprendizado já determinado pelo professor no modelo antigo de educação, é substituído pela necessidade de aprender a aprender, desenvolvendo-se, assim, habilidades para a era da informação (Heide \& Stilborne, 2000).

A partir da experiência de reestruturação curricular já reconhecida do Projeto Amora (Colégio de Aplicação-UFRGS) nossa necessidade de formação de parcerias, a saber, principalmente com escolas públicas brasileiras, nos levou a utilizar os meios telemáticos para a criação de possibilidades de comunicação que sem eles não poderiam existir. Num histórico mais recente, destacamos o projeto Educadi (CNPQ), a formação de professores nos cursos de especialização do Proinfo (SEED-MEC) e o concurso Sua Escola a 2000 por hora do Instituto Ayrton Senna, como os principais movimentos nos quais tivemos participação efetiva e que nos levam a fazer as reflexões que se seguem sobre alguns dos recursos que utilizamos.

\section{O webfólio}

As escolas parceiras do concurso Sua Escola a 2000 por hora compartilham sua rotina através de um webfólio publicado na página do programa. Cada webfólio apresenta dados gerais sobre a escola e espaço para o registro dos projetos pedagógicos desenvolvidos, bem como de atividades diárias. O webfólio permite ao usuário atualizar informações, bem como manter-se informado sobre os demais parceiros. Não é possível alterar dados ou fornecer contribuições ao webfólio sem o acesso com senha, o que garante a cada escola o controle das informações postadas. Geralmente o administrador do webfólio é o professor, no entanto o preenchimento pode ser feito de acordo com os interesses dos alunos. A administração geral dos webfólios junto à página do Programa Sua Escola a 2000 Por Hora é feita pelo próprio Instituto Ayrton Senna.

\begin{tabular}{|c|c|c|}
\hline \multicolumn{2}{|c|}{ Colégio de Aplicação - UFRGS } & 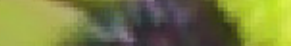 \\
\hline $\begin{array}{l}\text { Dados da escola: } \\
\text { Av. Bento Gonçalves, } 9500 \\
\text { Porto Alegre - RS } \\
\text { Tel.: (0x×51) } 33166977-3316 \\
6951 \\
\text { Diretor(a): Jorge Luiz Day Barreto } \\
\text { Apelido: rs-aplicacao }\end{array}$ & $\begin{array}{l}\text { Projetos da Escola: } \\
\text { Projeto Amora - } \\
\text { http://amora, cap.ufrgs.br }\end{array}$ & a $=$ \\
\hline Conquistas e Desafios & Diário de Bordo & \\
\hline $\begin{array}{l}\text { Tema: } \\
\text { Uma nova ferramenta }\end{array}$ & $13 / 01 / 2003$ & \\
\hline $\begin{array}{l}\text { Resumo da conquista } \\
\text { Publicação das páginas dos }\end{array}$ & $\begin{array}{l}\text { Fórum de Projetos - Es } \\
\text { de janeiro, o II Fóru } \\
\text { ladresentados os traba }\end{array}$ & $\begin{array}{l}\text { jado para quarta-feira, dia } \\
\text { rojetos } 2002 \text {, no qual ser } \\
\text { Desauisa dos alunos sob }\end{array}$ \\
\hline
\end{tabular}


Figura 1 - Webfólio do Colégio de Aplicação na página do Programa Sua Escola a 2000 Por Hora

Alguns webfólios oferecem oportunidade de interação assíncrona, através do preenchimento de enquetes e no acesso à página de cada escola, cujos links estão disponíveis.

Nos cursos de formação de professores do Proinfo, os webfólios são construídos pelos professores e acessados a partir da publicação de páginas da Internet. Dessa forma, o aluno (ou professor-aluno) produz seus relatos e determina a sua organização de acordo com a sua própria necessidade. Além disso, a aparente maior dificuldade a ser enfrentada (a necessidade do uso de um editor de páginas e de fazer a publicação das mesmas) leva-nos a necessidade de produzir uma apropriação de alguns recursos tecnológicos imprescindível ao uso pedagógico da Internet.

"Sem dúvida, a interconectividade atingida através da Internet é muito maior do que a que vivemos há cem ou cinqüenta anos através do telégrafo, rádio ou telefone. Todavia nós ainda fazemos com a Internet nada mais nada menos do que o que desejamos no domínio das opções que ela oferece, e se nossos desejos não mudarem, nada muda de fato, porque continuamos a viver através da mesma configuração de ações (de emocionar) que costumamos viver". (Maturana, 2001, p. 199)

Vemos que, neste formato, o webfólio tem poucas possibilidades do ponto de vista da interação. Embora seja um recurso bastante interessante para dar visibilidade, em um único lugar, da rotina dos trabalhos de cada um dos parceiros, ele precisa ser complementado por outros que possibilitem discussões sobre o que é relatado.

\section{Listas e fóruns de discussão}

A participação em listas e fóruns de discussão permite ao usuário a interação com os parceiros tanto no que se refere à troca de informações e discussão de cunho teórico, quanto à resolução conjunta de problemas. Por permitir a expressão, discussão e contraposição de idéias entre os sujeitos, é um recurso que promove a aprendizagem e possibilita a construção do conhecimento.

“É preciso criar situações para que esse aluno estabeleça relações. Para que estabeleça relações entre relações, que faça construções renovadas e reinvente as noções que se pretende que ele aprenda. Só assim se alcança a compreensão de um conhecimento". (Nitzke, 2002) 


\begin{tabular}{|c|c|}
\hline $\begin{array}{l}\text { Grupos de } \\
\text { Discussão }\end{array}$ & Educação Ambiental (educ-amb) \\
\hline \multirow{4}{*}{$\begin{array}{l}\text { Estes grupos } \\
\text { proporcionam } \\
\text { interação, } \\
\text { troca de idéias e } \\
\text { aprendizagem sobre } \\
\text { um tema específico. } \\
\text { Para participar clique } \\
\text { em inscrição. }\end{array}$} & $\begin{array}{l}\text { Grupo de discussão sobre práticas criativas e reflexões acerca } \\
\text { Ambiente. }\end{array}$ \\
\hline & $\begin{array}{l}\text { Coordenadora: Lenise Garcia. } \\
\text { Quatro Pilares da Educação (4pilares) }\end{array}$ \\
\hline & $\begin{array}{l}\text { Grupo de discussão sobre Os Quatro Pilares e o Desenvolvime } \\
\text { Competências e Habilidades. }\end{array}$ \\
\hline & Coordenador: Eduardo Chaves. \\
\hline Descriçäo & Uso Inovador da Tecnologia (educ-tec) \\
\hline Inscriçao & $\begin{array}{l}\text { Grupo de discussão sobre o uso inovador e criativo das Novas } \\
\text { Ternnlnnias. }\end{array}$ \\
\hline \multicolumn{2}{|c|}{ Grupos de Discussäo - Microsoft Internet Explorer } \\
\hline $\begin{array}{l}\text { Grupos de } \\
\text { Discussão }\end{array}$ & Educação Ambiental (educ-amb) \\
\hline \multirow{4}{*}{$\begin{array}{l}\text { Estes grupos } \\
\text { proporcionam } \\
\text { interação, } \\
\text { troca de idéias e } \\
\text { aprendizagem sobre } \\
\text { um tema específico. } \\
\text { Para participar clique } \\
\text { em inscriçăo. }\end{array}$} & $\begin{array}{l}\text { Grupo de discussão sobre práticas criativas e reflexões acerca } \\
\text { Ambiente. }\end{array}$ \\
\hline & $\begin{array}{l}\text { Coordenadora: Lenise Garcia. } \\
\text { Quatro Pilares da Educação (4pilares) }\end{array}$ \\
\hline & $\begin{array}{l}\text { Grupo de discussão sobre Os Quatro Pilares e o Desenvolvime } \\
\text { Competências e Habilidades. }\end{array}$ \\
\hline & Coordenador: Eduardo Chaves. \\
\hline Descriçăo & Uso Inovador da Tecnologia (educ-tec) \\
\hline Inscriçâ & $\begin{array}{l}\text { Grupo de discussão sobre o uso inovador e criativo das Novas } \\
\text { Ternnlnnias. }\end{array}$ \\
\hline
\end{tabular}

Figura 2 - Tela principal dos Grupos de discussão da página do Programa Sua Escola a 2000 Por Hora
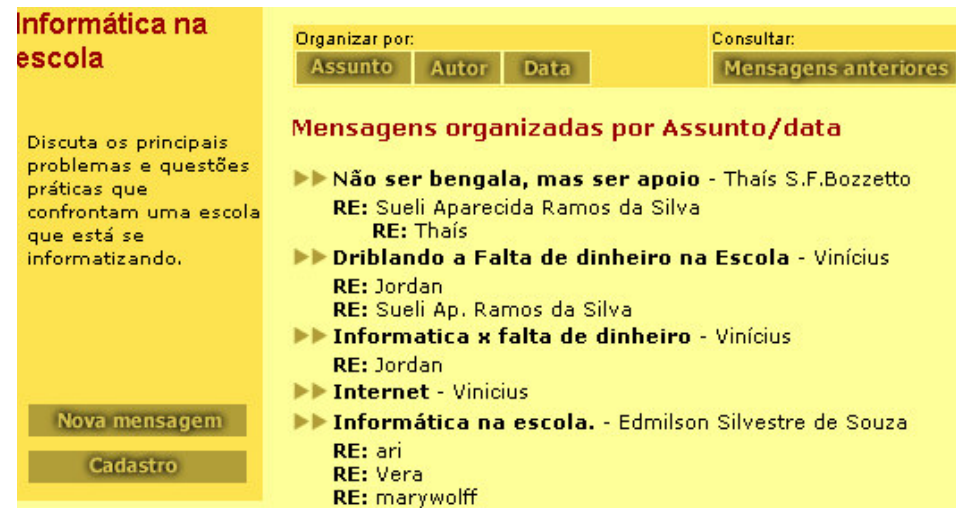

Figura 3 - Página inicial da lista de discussão sobre Informática na Escola do Programa Sua Escola a 2000 Por Hora

Tanto as listas quanto os fóruns de discussão podem abranger várias temáticas, as quais são organizadas de forma a permitir a participação do usuário em cada uma delas. Na Figura 2 temos a tela inicial dos Grupos de Discussão, na qual o internauta pode escolher dentre três temas. Ao cadastrar-se, começa a fazer parte de uma lista de discussão, recebendo mensagens através do correio eletrônico e interagindo apenas com 
usuários interessados no tema selecionado. Já na Figura 3 é apresentada uma das telas dos Fóruns de Discussão que se desenvolvem a partir do acesso direto à página do programa. O usuário escolhe o tema que lhe interessa, faz o cadastro e sua participação depende da conexão ao ambiente.

No Projeto Amora, utilizamos os fóruns de discussão como mais uma possibilidade de interação com os alunos em trabalhos de construção coletiva orientados por um professor: os projetos de aprendizagem. Esses últimos, surgem de temas e perguntas decididos pelos alunos e cuja orientação deve abranger assuntos muitas vezes diferentes da área de formação dos professores. Assim, os fóruns permitem a participação de especialistas de outras áreas nos projetos dos alunos que estão também visíveis porque os alunos constroem e publicam páginas da Internet sobre os assuntos que estão estudando.

\section{Bloggers}

$\mathrm{O}$ uso de bloggers tem se difundido nas escolas por permitir o registro de forma rápida e simples. $\mathrm{O}$ blog funciona como um diário no qual o usuário (aluno ou professor) pode registrar atividades, eventos ou impressões acerca de determinado assunto. Ao contrário do webfólio apresentado, que se refere às atividades de cada escola, o blog tem sido utilizado pelas escolas parceiras também como registro de grupo, uma vez que, compartilhado o endereço da publicação, vários usuários podem acrescentar informações ao diário construído.

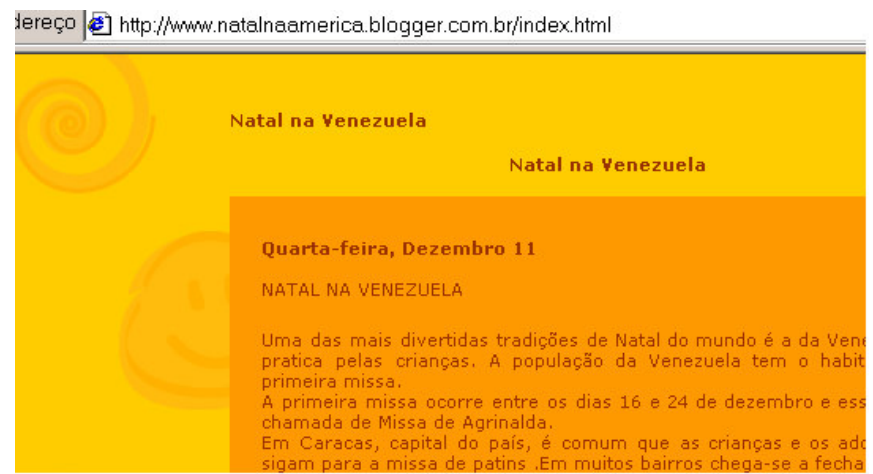

Figura 4 - Blog construído por um aluno para o Jornal Virtual do Programa Sua Escola a 2000 Por Hora

A construção de um blog pode ser feita, por exemplo, a partir do site www.blogger.com.br. Uma vez feito um cadastramento do usuário e definida uma senha, ela qual pode ser compartilhada por um grupo no caso de construção coletiva. É possível inserir imagens e alterar os dados postados. Os alunos e professores parceiros têm desenvolvido bloggers para relatar atividades, documentar eventos e planejar desafios cooperativos. $\mathrm{O}$ acesso ao blog é feito diretamente no endereço de publicação, portanto mesmo que a escola não tenha página pode fazer os registros utilizando o acesso à Internet. A construção de um blog de forma cooperativa também possibilita a interação entre os sujeitos e promove a troca de idéias e a resolução de desafios de forma colaborativa. 


\section{Mapas conceituais}

Tem sido muito difundido, ultimamente, o uso de mapas conceituais nas mais diversas etapas do processo educacional. Um mapa conceitual, de acordo com Novak, é uma ferramenta para armazenar e organizar conhecimento. Eles incluem conceitos (geralmente armazenados em caixas ou círculos) e as relações entre eles que indicam uma conexão entre conceitos.

É farta a literatura sobre o uso de mapas conceituais atualmente, bem como os seus diferentes usos (Araújo, 2002). Por outro lado, de acordo com a abordagem que estamos propondo nesse artigo, a sua utilização, como forma compartilhar e construir conhecimento, parece ainda centrada nos resultados finais dos mapas, bem como na determinação de modelos "corretos" de conhecimento a serem comparados com os mapas conceituais construídos.

A ferramenta CMap Tools, desenvolvida no Institute for Human and Machine Cognition da University of West Florida, nos permite construir mapas conceituais e publicá-los em servidores, bem como transformá-los em figuras que podem ser publicadas em páginas da Internet.

Temos utilizado a construção dos mapas conceituais tanto por alunos quanto por professores como forma de possibilitar a tomada de consciência dos aprendizes, e nesse caso nos consideramos - professores - também aprendizes, das diversas relações existentes nos conceitos trabalhados em um currículo. Isso nos leva, nas discussões, a produzir deslocamentos das propostas metodológicas para que atendam à necessidade de construção evidenciada nas relações expressas pelos mapas conceituais.

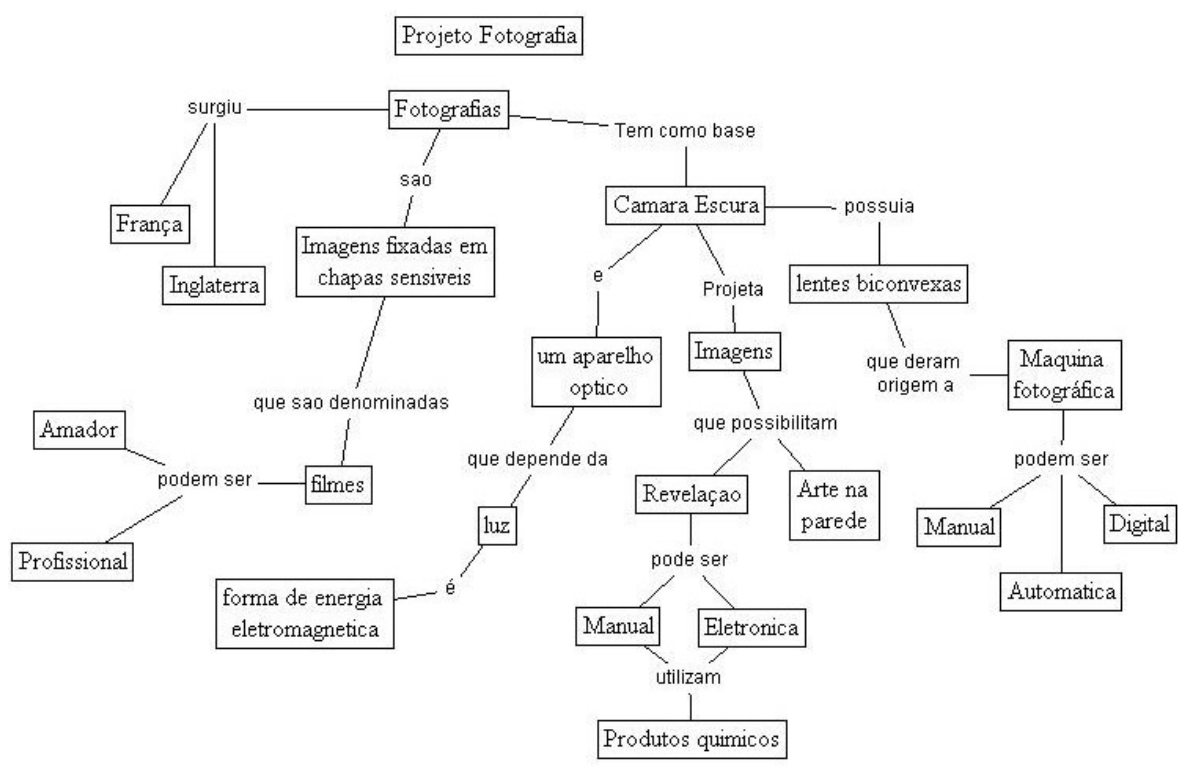

Figura 5 - Mapa conceitual produzido por professores que orientavam um projeto sobre fotografia 
Por exemplo, na figura acima, um mapa conceitual construído por professores orientadores de um projeto de aprendizagem sobre fotografia, possibilitou, a partir da discussão do mapa tanto por colegas professores de outras áreas quanto pelos próprios alunos, a preparação de atividades interdisciplinares com a intenção de esclarecer melhor os conceitos envolvidos nesse projeto.

Mais uma vez, a interação parece ter sido o principal operador de transformação e construção. Assim, aliado ao compartilhamento dos mapas, as discussões geradas tanto em Fóruns ou listas, ou ainda chats, recriam e ampliam as construções individuais ou dos pequenos grupos a partir dos confrontos de experiências e conhecimentos da comunidade que a parceria á distância cria.

\section{Conclusões}

Escolhemos, da nossa experiência como docentes, alguns recursos tecnológicos disponíveis àqueles que tem acesso a Internet que foram testados em situações diferentes. As reflexões que nos levaram a escrever esse artigo, encaminham nosso trabalho a uma aposta cada vez maior nas possibilidades de construção de conhecimento coletivo, compartilhado em redes e, sobretudo, que respeite a ação dos envolvidos nesse processo. Esperamos contribuir com a discussão cada vez mais presente de reformulações nas propostas de estruturação do trabalho na escola.

\section{Referências bibliográficas}

ARAÚJO, A. M. T. MENEZES, C. S. CURY, D. Um ambiente integrado para apoiar a avaliação da aprendizagem baseado em mapas conceituais. In Simpósio Barsileiro de Informática na Educação, 13., 2002, São Leopoldo-RS. Anais. São Leopoldo: Sociedade Brasileira de Computação, 2002, p. 49-59.

CMAP TOOLS. Software para construção de mapas conceituais da University of West Florida. Disponível em <http://cmap.coginst.uwf.edu>. Acessado em fev/2003.

HEIDE, A. STILBORNE, L. Guia do Professor para a Internet Completo e Fácil. Porto Alegre: Artmed, 2000.

MATURANA, H. Metadesign In MAGRO, C. \& PAREDES,V. (orgs.) Cognição, ciência e vida cotidiana. Belo Horizonte: Editora UFMG, 2001, p.173-200.

NITZKE, J. A. CARNEIRO, M. L. F. FRANCO, S. R. K. Ambientes de Aprendizagem Cooperativa Apoiada pelo Computador e sua Epistemologia. In: Informática na Educação: teoria \& prática. Porto Alegre: UFRGS. Programa de Pós-Graduação em Informática na Educação, 2002. 
NOVAK J. D. The Theory Underlying Concept Maps and How To Construct

Them. Disponível em <http://cmap.coginst.uwf.edu/info/printer.html>. Acessado em: dez/2002.

PROGRAMA NACIONAL DE INFORMÁTICA NA EDUCAÇÃO. Programa da Secretaria de Educação à distância do MEC. Disponível em $<$ http://eproinfo.proinfo.mec.goc.br>. Acessado em fev/2003.

PROGRAMA SUA ESCOLA A 2000 POR HORA. Programa do instituto Ayrton Senna com a parceira da Microsoft Brasil. Disponível em $<$ http://escola2000.globo.com/>. Acessado em fev/2003.

PROJETO AMORA, desenvolvido pelo Colégio de Aplicação da UFRGS desde 1996. disponível em <http://amora.cap.ufrgs.br>. Acessado em: dez/2002.

PROJETO EDUCADI, desenvolvido com o apoio do CNPQ pelo Laboratório de Estudos Cognitivos da UFRGS, 1997-1998. Disponível em $<$ http://educadi.psico.ufrgs.br>. Acessado em fev/2003. 